\title{
Occupational Stress and How to Confront It: A Case Study of a Hospital in Shiraz
}

\author{
Tahereh Shafaghat ${ }^{1}$, Mohammad Kazem Rahimi Zarchi ${ }^{1 *}$, Zahra Kavosi ${ }^{1}$ \\ 'Department of Health Services Management, School of Public Health, Shiraz University of Medical Sciences, Shiraz, \\ Iran
}

*Corresponding Author: Mohammad Kazem Rahimi Zarchi, Ph.D., Department of Health Services Management, School of Public Health, Shiraz University of Medical Sciences, Shiraz, Iran. Tel: +98-9132529084,

Email: rahimi_99@yahoo.com

Received February 23, 2018; Accepted April 18, 2018; Online Published May 5, 2018

\begin{abstract}
Background: Although all jobs can be stressful, occupational stress is an important issue in jobs that deal with human health. Evidence indicates that nursing is a stressful occupation.

Objective: This research evaluated factors affecting occupational stress and strategies for coping with it.

Methods: This cross-sectional descriptive-analytic study was conducted in 2015. The study population comprised all nurses at Shahid Rajaee hospital, from whom 190 nurses were selected by random sampling. Data was collected by questionnaire and analyzed using SPSS software (version 19), Pearson correlation coefficient tests, Mann-Whitney tests, and t tests.

Results: Occupational stress was rated as moderate among the studied nurses. Significant positive correlations were found between occupational stress level and less effective coping method, occupational stress level and work experience level, and ineffective coping methods and age. Moreover, a significant difference was seen between men and women in terms of emotion-focused coping.

Conclusion: According to the research findings, occupational stress was at a moderate level among the studied hospital nurses, indicating that the authorities need to focus on efforts to reduce occupational stress for nurses.

Keywords: Occupational Stress, Nurses, Hospital
\end{abstract}

\section{Background}

Stress is a part of daily life. It is a psychological state or the process that occurs when a person is faced with an event he perceives as threatening to his physical and psychological welfare. It stems from interactions with one's environment and inconsistencies between the pressures of a situation and one's resources. ${ }^{1,2}$ Stress has become significantly important in occupational health with globalization, promotion of competition, increased movement between nations, and changing employment relationships. Moreover, it has been identified as a major cause of economic loss throughout the world. ${ }^{3}$

One of the most important sources of stress in each person's life is employment. Occupational stress has become a common and costly problem in workplaces. ${ }^{4}$ It is one of the main reasons for reduced productivity in organizations, and it has physical and psychological effects on employees. ${ }^{5,6}$ Occupational stress is much more important in the field of healthcare, because healthcare services delivery is very laborious and risky. To achieve quality, efficiency, effectiveness, and equity in these types of services, conditions must be appropriate and accompanied by the reduction of stress in employees. Nurses are continually exposed to stress because of the sensitive nature of their profession. Nurses in parts of a hospital are regular, sympathetic, and interested people when they enter the nursing profession; after a few years of working and facing a lot of occupational stress, they become fatigued and tend to withdraw from their work. ${ }^{8}$

There are many stressful things in the work environment of nurses, the most important of which are the unavailability of doctors in emergencies, low staff-to-patient ratios, shortages in and unavailability of required facilities, contact with patients and contaminated equipment and discharge, incompatibility between work schedules and living conditions, care of critically ill and dying patients, reactions of patients' relatives, time limitations, ${ }^{9}$ lack of sufficient readiness and skills to meet the needs of patients and their families, commuting of relatives and very noisy customers, ${ }^{8}$ dealing with the pain and suffering of patients, seeing and doing therapeutic and care interventions in unpleasant scenes such as reclamation, contradictions in

Copyright $\odot 2018$ The Author(s). This is an open-access article distributed under the terms of the Creative Commons Attribution License (http:// creativecommons.org/licenses/by/4.0), which permits unrestricted use, distribution, and reproduction in any medium, provided the original work is properly cited. 
duties, variable shifts, critical space, contact with various chemicals and harmful diagnosis-therapeutic radiation, ${ }^{10}$ workflow, long working hours, ${ }^{1}$ problems associated with physicians, colleagues, head nurses and supervisors, ${ }^{1,8}$ and lack of support. ${ }^{1}$

Based on the above findings, this study aimed to evaluate stressful factors affecting nurses at Shiraz Rajaee (trauma) hospital to help hospital managers provide proper workplace conditions for nurses by becoming aware of the occupational stress level of nurses and their coping methods.

\section{Objective}

This research evaluated the factors affecting occupational stress and coping strategies to help hospital authorities make better decisions for their personnel.

\section{Methods}

This cross-sectional, descriptive-analytic study was conducted in 2015. The study population comprised all nurses at Shahid Rajaee hospital, from whom 190 were selected by random sampling.

Data was collected by questionnaires. The first was a standard questionnaire used to measure occupational stress levels. The Cronbach's alpha for this questionnaire was $0.92 .{ }^{11}$ The questionnaire consisted of 10 questions in 3 dimensions in the area of occupational stress. The first 3 questions were related to the physical environment dimension, the next 4 questions were related to work conflict, and the last 3 questions were related to the dimension of role ambiguity. Questions were answered with scores as follows: never $=0$, rarely $=1$, sometimes $=2$, often $=3$, always $=4$. The total score was the sum of answers in each dimension. A score of less than $25 \%$ of the total possible score indicated no stress, $25 \%$ to $50 \%$ indicated a natural level of stress, $50 \%$ to $75 \%$ indicated a moderate stress level, and $75 \%$ to $100 \%$ indicated an extreme stress level (Table 1).

The second questionnaire was a checklist of ways to deal with mental pressure. It was a multi-dimensional tool that investigated the methods nurses used to respond to psychological pressure. The checklist was based on Lazarus' model of stress and coping and the behavioral self-regulation model by Carver et al. ${ }^{12}$ It was translated by Ebrahimi et $\mathrm{al}^{13}$ and revised based on Iranian culture and numerous other existent scales. It contained 72 questions in 18 groups, and each group was composed of 4 items. The validity and reliability of this tool was previously investigated by Carver et $\mathrm{al}^{12}$ in 3 separate studies. The first 5 scales of the checklist were allocated to measuring problem-focused coping methods that included active confronting, planning, and prevention of pesky activity; avoiding hasty dealings with the problem of continence; and searching for social support. The second 5 scales were allocated to measuring emotion-focused coping strategies, which included seeking emotional support; ignoring; turning to religion; acceptance; and positive reinterpretation confronting. The third 3 scales measured less effective coping methods that included lack of intellectual involvement; no behavioral conflict; and focus on emotion and its tools. The final 5 scales were allocated to measuring ineffective coping strategies that included impulsivity; superstitions; wishfulness; negative thinking; and the use of drugs and narcotics.

Researchers distributed questionnaires among nurses at the studied hospital after describing the research and ensuring the participants of confidentiality and honesty in reporting the research results. A total of 190 questionnaires were distributed, and 180 answers were received. After data was collected, it was analyzed with SPSS software (version 19), the Pearson correlation test, the Mann-Whitney test, and the $t$ test.

\section{Results}

According to the findings, the stress level of most nurses was normal in terms of the work conflict dimension and role ambiguity; it was moderate in terms of the physical environment. A moderate level of general occupational stress was observed in more nurses (63.6\%) (Table 2), and the majority of nurses used problem-focused coping methods to deal with stressful situations (Table 3).

There was a significant positive correlation between occupational stress and less effective coping methods $(P<0.05)$. This means that when stress increased, the nurses more often used less effective coping techniques to deal with it (Table 4).

Occupational stress levels in nurses had a significant, positive correlation with work experience $(P<0.05)$. A positive relationship was also seen between ineffective coping methods and age $(P<0.05)$ (Table 5). The relationships of occupational stress and stress-related coping strategies with the variables of age and work experience were analyzed using the Pearson correlation test.

No significant relationship was found between occupational stress, less effective coping strategies, or ineffective coping strategies and the gender or marital status of nurses $(P>0.05)$. A significant difference was seen

Table 1. Categories of Occupational Stress and its Dimensions Based on Scores

\begin{tabular}{|c|c|c|c|c|}
\hline Occupational Stress Dimension & No Stress & Natural Stress & Moderate Stress & Extreme Stress \\
\hline Physical dimension & $0-3$ & $3.1-6$ & $6.1-9$ & $9.1-12$ \\
\hline Work conflict & $0-4$ & $4.1-8$ & $8.1-12$ & $12.1-16$ \\
\hline Role ambiguity & $0-3$ & $3.1-6$ & $6.1-9$ & $9.1-12$ \\
\hline Job stress & $0-10$ & $10.1-20$ & 20.1-30 & $30.1-40$ \\
\hline
\end{tabular}


Table 2. Frequency Distribution of Stress and its Dimension in Nurses

\begin{tabular}{|c|c|c|c|c|c|c|c|c|}
\hline \multirow{2}{*}{$\begin{array}{l}\text { Intensity of Occupational Stress } \\
\text { Dimensions }\end{array}$} & \multicolumn{2}{|c|}{ Without Stress } & \multicolumn{2}{|c|}{ Natural Stress } & \multicolumn{2}{|c|}{ Moderate Stress } & \multicolumn{2}{|c|}{ Intensive Stress } \\
\hline & No. & $\%$ & No. & $\%$ & No. & $\%$ & No. & $\%$ \\
\hline Physical environment & 3 & 1.8 & 21 & 12.7 & 82 & 49.7 & 59 & 35.8 \\
\hline Work conflict & 9 & 5.5 & 77 & 46.7 & 65 & 39.4 & 14 & 8.5 \\
\hline Role ambiguity & 34 & 20.6 & 87 & 52.7 & 38 & 23.0 & 6 & 3.6 \\
\hline Occupational stress & 6 & 3.6 & 45 & 27.3 & 105 & 63.6 & 9 & 5.5 \\
\hline
\end{tabular}

between women and men in terms of emotion-focused coping $(P<0.05)$, such that women used emotion-focused coping methods to deal with stress more than men. A significant difference was also seen between married and single nurses in terms of using problem-focused coping methods $(P<0.05)$; single nurses used problem-focused coping methods more than married nurses.

The $t$ test was used to investigate the relationship between occupational stress and the variables of age and marital status and between less effective and ineffective coping methods and the variable marital status. The MannWhitney test was used to evaluate the relevance of each of 4 coping methods with gender and problem-focused and emotion-focused coping methods with marital status. It is noteworthy that the average rating calculated by the Mann-Whitney test was different than the average number of different grades (Table 6).

\section{Discussion}

According to the research findings, occupational stress among nurses in the studied hospital was at a moderate

Table 3. Mean and Standard Deviations of Stress-Related Coping Methods

\begin{tabular}{lll}
\hline Coping Methods & Mean & SD \\
\hline Problem-focused & 37.20 & 5.21 \\
Excitement-focused & 32.66 & 6.15 \\
Less effective & 17.81 & 2.65 \\
Not effective & 29.09 & 4.48 \\
\hline
\end{tabular}

Table 4. Correlation Between Occupational Stress and Coping Methods

\begin{tabular}{lcc}
\hline \multirow{2}{*}{ Stress-Related Coping Methods } & \multicolumn{2}{c}{ Job Stress } \\
\cline { 2 - 3 } & $\boldsymbol{r}$ & $\boldsymbol{P}$ \\
\hline Problem-focused & 0.081 & 0.300 \\
Excitement-focused & 0.129 & 0.100 \\
Less effective & 0.177 & 0.024 \\
Not effective & 0.041 & 0.606 \\
\hline
\end{tabular}

level, indicating that officials need to take action to reduce job stress for nurses in order to avoid its outcomes that could impose irreparable damage on the organization. Aghilinejad et $\mathrm{al}^{14}$ reported that occupational stress among nurses was at a moderate level; Hazavehei et al and Mardani Hamooleh et al came to the same conclusion. ${ }^{1,15}$ In addition, Donyavi et al investigated occupational stress among nurses in country military hospitals and reached the same conclusion. ${ }^{16}$ However, Asad Zandi et al reported that the rate of occupational stress among nurses is severe, ${ }^{17}$ and Kabirzadeh et al reported that occupational stress among nurses is in the normal range. ${ }^{18}$ Studies show that long and persistent stress in the workplace can lead to problems such as resignation, frequent absenteeism, reduced energy and working efficiency, reduced creativity, conflicts with colleagues, professional dissatisfaction, decreased quality of patient care, reduced accuracy and timeliness in decision-making, reduced ability and commitment among employees, feelings of inadequacy, depression, loss of job values, weariness, and fatigue from work. ${ }^{8}$

The current study identified the dimension of physical environment to be in the worst situation among all occupational stress dimensions. One explanation for this could be that some parts of the studied hospital were under construction and other parts were not located appropriately, which resulted in a lack of inter-sectional relations. Peyman Pak et al introduced conflicts with doctors and the lack of supportive resources as stressful factors. ${ }^{19}$ These results are not consistent with those of the current study. Torshizi and Ahmadi introduced 4 groups of factors affecting the incidence of occupational stress. The highest score among management factors was related to low salary in the work environment, and the highest mean score belonged to heavy traffic and crowd in part. The highest mean score affecting interpersonal relations in the incidence of occupational stress was related to the deficiency or lack of support from superiors, and the highest mean score among factors

Table 5. Correlation Between Job Stress and Coping Methods With Nurses' Demographics

\begin{tabular}{|c|c|c|c|c|}
\hline \multirow{3}{*}{ Coping Methods } & \multicolumn{4}{|c|}{ Demographic Characteristic } \\
\hline & \multicolumn{2}{|c|}{ Age } & \multicolumn{2}{|c|}{ Work Experience } \\
\hline & $R$ & $P$ & $R$ & $P$ \\
\hline Occupational stress & 0.135 & 0.084 & 0.160 & 0.043 \\
\hline Problem-focused & -0.058 & 0.464 & -0.015 & 0.849 \\
\hline Excitement-focused & -0.005 & 0.947 & 0.003 & 0.967 \\
\hline Less effective & -0.043 & 0.589 & -0.077 & 0.335 \\
\hline Not effective & 0.155 & 0.047 & 0.138 & 0.082 \\
\hline
\end{tabular}


Table 6. Relationship Between Occupational Stress and Coping Methods and Nurses' Demographics

\begin{tabular}{|c|c|c|c|c|c|}
\hline \multirow{3}{*}{ Stress and Coping Methods } & & \multicolumn{4}{|c|}{ Demographic Characteristics } \\
\hline & & \multicolumn{2}{|c|}{ Gender } & \multicolumn{2}{|c|}{ Marital Status } \\
\hline & & Male & Female & Married & Single \\
\hline \multirow{2}{*}{ Problem-focused } & Mean rank & 83.88 & 82.01 & 69.55 & 88.75 \\
\hline & $P$ & \multicolumn{2}{|c|}{0.822} & \multicolumn{2}{|c|}{0.010} \\
\hline \multirow{2}{*}{ Excitement-focused } & Mean rank & 65.11 & 89.50 & 84.70 & 79.36 \\
\hline & $P$ & \multicolumn{2}{|c|}{0.004} & \multicolumn{2}{|c|}{0.476} \\
\hline \multirow{3}{*}{ Less effective confronting } & Mean & 76.94 & 84.54 & 17.78 & 17.92 \\
\hline & Standard deviation & - & - & 2.57 & 2.68 \\
\hline & $P$ & \multicolumn{2}{|c|}{0.361} & \multicolumn{2}{|c|}{0.731} \\
\hline \multirow{3}{*}{ Ineffective } & Mean & 83.72 & 82.05 & 29.95 & 28.71 \\
\hline & Standard deviation & - & - & 4.18 & 4.62 \\
\hline & $P$ & \multicolumn{2}{|c|}{0.842} & \multicolumn{2}{|c|}{0.079} \\
\hline \multirow{3}{*}{ Job stress } & Mean & 22.68 & 23.49 & 23.26 & 22.08 \\
\hline & Standard deviation & 4.69 & 5.88 & 5.70 & 5.53 \\
\hline & $P$ & \multicolumn{2}{|c|}{0.850} & \multicolumn{2}{|c|}{0.191} \\
\hline
\end{tabular}

related to patient care belonged to non-scheduled meeting times. From 4 studied dimensions, Torshizi and Ahmadi introduced more average factors in the administrative dimension than in other dimensions. ${ }^{20}$ Moreover, the stress level in the job conflict and confusion dimensions was normal among nurses in a study by Barzideh et al, who also stated that role ambiguity is the most important factor on occupational stress. These results did not match the findings of the current study. Barzideh et al divided this dimension into several categories, such as freedom in decision-making, ability to use skills, and decision-making authority. ${ }^{3}$ Bahrami et al introduced role responsibilities and dual roles as the highest stressful factors for men and women, respectively. ${ }^{5}$

The current study found significant positive correlations between occupational stress and work experience and between ineffective coping method and age, which were enhanced in people with more work experience; people use more ineffective coping strategies to deal with stress as their age increases. Rahimian Boogar et al reached the same conclusion ${ }^{21}$ in his study, but other studies did not report any significant relationship between occupational stress and work experience., ${ }^{9,18,22}$ The current study found no significant relation between occupational stress and gender or marital status. Other researchers achieved similar results. ${ }^{9,18,22}$

A positive correlation between occupational stress and less effective coping methods was observed in the current study, indicating that the greater occupational stress among nurses is, the more they use less effective ways to reduce it. The findings also showed a significant difference between men and women in terms of emotion-focused coping, in agreement with the results of Bahrami et al. ${ }^{5}$ This could be due to differences in the natures of men and women; women are more emotional than men.

\section{Conclusion}

Occupational stress experienced by nurses can potentially have damaging and irreversible consequences. Not only

\section{Research Highlights}

\section{What Is Already Known?}

Job stress and lack of proper attention and control of it can lead to harmful effects on personnel performance and, consequently, providing appropriate services to patients.

\section{What This Study Adds?}

Study of the prevalence of occupational stress among employees, especially nurses, as well as searching for and providing solutions for effective coping with it, can have a significant effect on improving quality of life of the staff and improving their performance and provision of services to patients.

does it disturb the nurses' physical and psychological balance, it also decreases their performance, effectiveness, efficiency, and organizational commitment. Therefore, authorities should take action based on the results of this research to reduce physical environment stress factors, such as work-related injuries, improper ventilation in the workplace, etc. Nursing managers can also reduce the incidence of occupational stress by being aware of the study results, establishing proper communication with nurses, and creating the perfect environment for nurses to continue their professional activities.

\section{Authors' Contributions}

TS designed the study; MKRZ and ZK drafted, revised, and submitted the manuscript.

\section{Conflict of Interest Disclosures}

None.

\section{Ethical Approval}

This study was approved by the Shiraz University of Medical Sciences with code \#E-C-90-5820. 


\section{Acknowledgments}

The authors wish to express their appreciation to all nurses who participated in this research. This paper is the result of a research project by the Students Research Committee of the Shiraz University of Medical Sciences, approval number 5824-90.

\section{References}

1. Hazavehei MM, Hosseini Z, Moeini B, Moghimbeigi A, Hamidi Y. Assessing stress level and stress management among Hamadan hospital nurses based on PRECEDE model. Ofogh-eDanesh. 2012;18(2):78-85. [Persian].

2. Yoon $\mathrm{HS}$, Lee $\mathrm{KM}$, Kang D. Intercorrelation between Immunological Biomarkers and Job Stress Indicators among Female Nurses: A 9-Month Longitudinal Study. Front Public Health. 2014;2:157. doi:10.3389/fpubh.2014.00157.

3. Barzide M, Choobineh A, Tabatabaie SH. Aspects of job stress and its relation to stouts of the nurses public health. Journal of Occupational Medicine Specialist. 2012;4(3):2-17. [Persian].

4. Rezaei SH, Hosseini MA, Falahi M. Effect of communication skills teaching in job stress level among nurses occupying in rehabilitation center. Tehran Univ Med J. 2006;64(1):21-26.

5. Bahrami A, Akbari H, Mousavi SGA, Hannani M, Ramezani Y. Job stress among the nursing staff of Kashan hospitals. Feyz. 2011;15(4):366-373. [Persian].

6. Nurani Saedidin SH, Hadizadeh Talasaz Z, Shakeri MT, Modares Gharavi M. Study of relationship job stress with happiness in Mashhad hospital and health care centers midwives in 2013. Iranian Journal of Obstetrics, Gynecology and Obstetrics. 16(74):1-9. [Persian].

7. Salarian $\mathrm{MH}$, Sadr F. Process of the health sector reforms on productivity and motivation of human resources. Workshop Management Articles; 2007. [Persian].

8. Zeighami Mohammadi SH, Asgharzadeh Haghighi S. Study of relationship between job stress and burnout in nurses. Scientific Journal of Hamadan University of Medical Sciences. 2011;19(2):42-49. [Persian].

9. Hebrani P, Behdani F, Mobtaker M. Study of stress in nurses. Evaluation of Stress Factors in Nurses of Different Hospital Wards. The Quarterly Journal of Fundamentals of Mental Health. 2008;10(3):231-237.

10. Darvishpoor Kakhki A, Ebrahim H, Alavi Majd H. health status of nurses of hospitals dependent to Shahroud Medical University. Iran Journal of Nursing. 2009;22(60):19-27.

11. Khanian S. Study of relationship between job stress and time management among managers of Shiraz health care centers [dissertation]. Shiraz: School of Management and Medical Information, Shiraz University of Medical Sciences; 2007. [Persian].

12. Carver CS, Scheir MR, Weintraub JK. Assessing coping strategies: a theoretically based approach. J Pers Soc Psychol. 1989;56(2):267-83. doi:10.1037/0022-3514.56.2.267.

13. Ebrahimi A, Bolhari J, Zolfaghari F. Stress coping strategies and social support in depressive veterans with spinal cord injury. Iranian Journal of Psychiatry \& Clinical Psychology. 2002;8(2):40-48. [Persian].

14. Aghilinejad M, Attarchi MS, Golabadi M, Chehregosha $\mathbf{H}$. Comparing stress level of woman nurses of different units of Iran university hospitals in autumn 2009. Ann Mil Health Sci Res. 2010;8(1):44-48.

15. Mardani Hamooleh M, Ebrahimi E, Mostaghasi M, Taghavi Larijani T. Relationship between organizational justice and job stress among hospital personnel. J Med Ethics Hist Med. 2013;6(3):64-71.

16. Donyavi V, Koohian K, Soleiman Meigooni S, Akbari M. Survey of occupational stress scale on nurses in a military hospital in Tehran - 2012. Journal of Nurses and Physician Within War. 2012;19,20:9-13. [Persian].

17. Asad Zandi M, Sayari R, Ebadi A, Sanainasab H. Abundance of depression, anxiety and stress in militant Nurses. J Mil Med. 2011;13(2):103-108.

18. Kabirzadeh A, Mohseni Saravi B, Asghari Z, Bagherian Farahabadi E, Bagerzadeh Ladari R. Rate of General Health, Job Stress and Factors in Medical Records Workers. Health Inf Manag. 2007;4(2):215-222.

19. Peiman Pak F, Mansur L, Sadeghi M, Purebraham T. The Relationship of Job Stress with Marital Satisfaction and Mental Health in Nurses of Tehran Hospitals. Quarterly Journal of Career \& Organizational Counseling. 2013;4(13):27-54. [Persian].

20. Torshizi L, Ahmadi F. Job Stressors from Clinical Nurses' Perspective. Iran Journal of Nursing. 2011;24(70):49-60.

21. Rahimian Boogar E, Nouri A, Oreizy H, Molavi H, Foroughi Mobarake A. Relationship between Adult Attachment Styles with Job Satisfaction and Job Stress in Nurses. Iranian Journal of Psychiatry and Clinical Psychology. 2007;13(2):148-157. [Persian].

22. Hashemizadeh $H$. Analysis of relation between time management behaviors and occupational stress of medical surgical ward's Head Nurses of educational hospitals depend on shaheed beheshti medical university. The Quarterly Journal of Fundamentals of Mental Health. 2006;8(29-30):51-56. [Persian]. 